\title{
The Need for a Meaningful and Practical Classification of Asthma Severity
}

\author{
Demetrios S. Theodoropoulos, MD, Department of Allergy, Marshfield Clinic, Marshfield, Wisconsin
}

[See related article pp.155-163]

\section{REPRINT REQUESTS:}

Demetrios S. Theodoropoulos, MD

Department of Allergy

Marshfield Clinic

1000 North Oak Avenue

Marshfield, WI 54449

Telephone: $715-387-5186$

Fax: $715-389-3808$

Email: theodorpoulos.demetrios@marshfieldclinic.org

\section{KEYWORDS:}

Asthma; Severity of illness index; Therapeutics
Assessing asthma severity based on symptoms and convenient parameters, such as peak flow rates, is an indispensable method for the management of asthma. Several systems categorizing asthma severity have been developed in the United States of America, the United Kingdom, and Canada, and are routinely used to follow patients with asthma. In this issue of Clinical Medicine \& Research, Colice ${ }^{1}$ reviews the features, strengths and weaknesses of these systems. When making comparisons, it is difficult to avoid the temptation to seek the best system, although any of the developed classification systems may be as useful as the next. When it comes to practical outcomes, if applied properly and consistently, these systems are valuable tools for the management of asthma and the well being of patients. It is better to have a familiar and tried classification system, even if imperfect, than to have none. As an ancient Greek proverb states, "any measure could be the best one." The critical question in the development of any system to classify asthma severity is not in its applicability or easiness nor is it in the management of symptoms. It is in the optimal interpretation of the results, the ability to prognosticate, and especially the ability to assess the risk for fatal asthma; these are the major shortcomings of all current asthma classification systems.

Asthma is a rare phenomenon in modern medicine; in spite of technological advances, improvement in mortality rates have not been demonstrated. Instead, asthma mortality has been steadily increasing over the past thirty years, especially in inner city, African-American, and pediatric populations..$^{2,3}$ The mortality risk is not reflected in any of the current systems used for categorizing asthma severity. In fact $30 \%$ of all patients who die from asthma have been characterized as mild asthmatics just prior to their fatal exacerbation. Furthermore, bronchial biopsy and bronchoalveolar lavage studies have shown inflammatory changes in the airways of cases of mild asthma, even at times when there was no asthma exacerbation. ${ }^{3,4}$ Thus it appears that, at least as far as mortality risk and ongoing inflammation are concerned, there is nothing mild about "mild asthma".

Increasing asthma mortality, wide exposure of all asthma severity groups (including mild and moderate) to fatal outcome, and evidence of persistent inflammation during remission of asthma symptoms are the challenges for all current asthma severity classifications. Dr. Colice's review highlights the pathology of asthma as an 
inflammatory disease, the discrepancy between the severity of asthma symptoms and the severity of ongoing, underlying inflammation, and the need for regular clinical assessment of asthma control. Colice concludes with the need for developing and implementing an "index of airway inflammation" based on objective findings.

\section{REFERENCES}

1. Colice GL. Categorizing asthma severity: an overview of national guidelines. Clinical Medicine and Research 2004;2:155-163.

2. Mannino DM, Homa DM, Pertowski CA, Ashizawa A, Nixon LL, Johnson CA, Ball LB, Jack E, Kang DS. Surveillance for asthma-United States. 1960-1995. MMWR Surveill Summ1998;47(SS-1):1-28.

3. Robertson CF, Rubinfeld AR, Bowes G. Pediatric asthma deaths in Victoria: the mild are at risk. Pediatr Pulmonol 1992;13:95-100.

4. Beasley R, Roche WR, Roberts JA, Holgate ST. Cellular events in the bronchi in mild asthma and after bronchial provocation. Am Rev Respir Dis 1989;139:806-817. 